\title{
Comparison of short-term therapeutic effects between laparoscopic surgery and laparotomy combined with new adjuvant radiochemotherapy in progressive stage-rectal carcinoma.
}

\author{
Lei Yao" ${ }^{1 \#}$, Lan Ye" ${ }^{2 \#}$ Chungang Fan², Yi Luo², Jianhua Meng ${ }^{2 *}$ \\ ${ }^{1}$ Department of Gastrointestinal Urology, Tianyou Hospital Affiliated of Wuhan University of Science and Technology, \\ Wuhan, Hubei, PR China \\ ${ }^{2}$ Department of Oncology, the Second Hospital of Wuhan Iron And Steet (Group) CORP, Wuhan, Hubei, PR China
}

\#These authors contributed equally to this paper

\begin{abstract}
Objective: This study aimed to discuss the short-term therapeutic effects of laparoscopic surgery and laparotomy with new adjuvant radiochemotherapy on rectal carcinoma in the progressive stage.

Methods: A total of 120 patients with rectal carcinoma in our hospital from May 2014 to February 2016 were selected and categorized into the control group $(n=60)$ and treatment group $(n=60)$ by random number table method. All respondents were simultaneously treated by new adjuvant radiochemotherapy. The control group was treated by laparotomy, whereas the treatment group received laparoscopic surgery. Operation mode, intraoperative conditions, post-operative rehabilitation effect, and occurrence rate of complications in the near future were compared between the two groups.

Results: No significant difference of operation mode (e.g., Dixon operation, Miles operation, and Hartmann operation) was observed between the treatment group and control group $(\mathbf{P}>0.05)$. The operation time of the control group was shorter than that of the treatment group, but the intraoperative blood loss of the treatment group was far higher $(\mathbf{P}<\mathbf{0 . 0 5})$. No significant differences were found between the two groups in terms of cases of intraoperative blood transfusion, remote cutting marginal distance of Dixon operation, number of assessable lymph glands, number of lymphoma transfer, and cases of terminal ileum fistulization of Dixon operation $(P>0.05)$. The time of exhaustion, time of defecation, and time of feeding after operation and Length of Stay (LOS) of the treatment group were shorter than that of the control group $(\mathbf{P}<\mathbf{0 . 0 5})$. The control group and treatment group presented no statistically significant difference in view of the occurrence rate of post-operative complications $(\mathbf{P}<0.05)$.

Conclusions: Laparoscopic surgery combined with new adjuvant radiochemotherapy has outstanding therapeutic effect on rectal carcinoma in the progressive stage and high safety. It can be promoted as the first clinical therapy for rectal carcinoma in the progressive stage.
\end{abstract}

Keywords: New adjuvant radiochemotherapy, Laparotomy, Laparoscopic surgery, Rectal carcinoma, Progressive stage. Accepted on November 30, 2017

\section{Introduction}

Rectal carcinoma is a common gastrointestinal tumor in clinics and accounts for about $70 \%$ in total colorectal cancer [1]. Recent applications and development of new adjuvant radiochemotherapy contribute its outstanding progresses in clinical therapy of locally advanced rectal carcinoma. This treatment can relieve tumor loads to some extent, reduce gross tumor volume significantly, and increase the success rate of excision [2]. In particular, this therapy creates opportunities to the application of inguinal orchiectomy and apparently increases the rate of anal preservation. At present, radical operation is the first choice for locally advanced rectal carcinoma [3]. With the promotion and generalization of laparoscopic radical rectectomy for rectal cancer in clinics, its therapeutic effect has won trust and approval of attending doctors and patients [4]. In this study, 120 patients with rectal carcinoma in the progressive stage in our hospital from May 2014 to February 2016 were selected as the research subjects. Research results are introduced in the following text.

\section{Information and Methods}

\section{General information}

A total of 120 patients with rectal carcinoma in our hospital from May 2014 to February 2016 were selected and divided into the control group $(n=60)$ and treatment group $(n=60)$ by 
random number table method. The control group had 36 males and 24 females with ages of $24-80(53.8 \pm 4.2)$ in average. The control group had 10 cases of mucinous adenocarcinoma, 27 cases of poorly differentiated adenocarcinoma, 12 cases of moderately differentiated adenocarcinoma, and 11 cases of highly differentiated adenocarcinoma. Among them, 32 cases had complications with hypertension, 20 cases with diabetes, and 28 cases with coronary heart disease. The treatment group had 38 males and 22 females with ages of 25-81 (54.9 \pm 4.1$)$ in average. Meanwhile, the treatment group had 9 cases of mucinous adenocarcinoma, 25 cases of poorly differentiated adenocarcinoma, 14 cases of moderately differentiated adenocarcinoma, and 12 cases of highly differentiated adenocarcinoma. Among them, 35 cases had complications with hypertension, 22 cases with diabetes, and 26 cases with coronary heart disease. General information of two groups were processed by the corresponding version of statistical software, which found no significant difference $(\mathrm{P}>0.05)$.

\section{Selection standards and exclusion standards}

Selection standards included the diagnosis of the adenocarcinoma of rectum by tissue biopsy, no distant metastasis, estimated feasible surgical excision, and menopause period of $\geq 12$ months. Possibilities of pregnancy were eliminated. Blood routine examination as well as liver, kidney, and cardio-pulmonary functions were examined after 2 $\mathrm{w}$ of concurrent radiochemotherapy before the operation. No surgical contraindication and surgical tolerance were found. Patients had no other forms of radiochemotherapy.

Exclusion standards included patients who used immunosuppressor and antineoplastic biological and radiochemotherapy before, had cognitive disorder or mental diseases, experienced allergic history or belonged to an allergic constitution, and had other types of malignant tumors or participated in other types of intervention clinical test.

\section{Treatment methods}

Radiochemotherapy: Conventional fractionated radiotherapy was performed to patients before operation by using Neusoft NMS-R600 linear top-speed device (1.8 Gy/time for five times/week). The total dosage was controlled within 45-50 Gy. Radiotherapy was carried out by FOLFOX4. Specifically, intravenous dripping of $100 \mathrm{mg} / \mathrm{m}^{2}$ oxaliplatin was offered at $\mathrm{d}$ 1. Moreover, intravenous dripping of $200 \mathrm{mg} / \mathrm{m}^{2}$ calcium folinate and intravenous dripping of $500 \mathrm{mg} / \mathrm{m}^{2} 5$-fluorouracil were given for $1-5 \mathrm{~d}$. One period lasted for $3 \mathrm{w}$, and two periods of therapy were offered. Operation was performed $2 \mathrm{w}$ after radiotherapy.

\section{Operation methods}

The control group used laparotomy, whereas the treatment group adopted laparoscopic surgery. Both groups selected total mesorectal excision and lymphadenectomy and implemented terminal ileum fistulization according to intraoperative conditions. The treatment group was operated by five-hole method, and sample incision was protected by notched protection bag.

\section{Observation indexes}

Operation modes included Dixon operation, Miles operation, and Hartmann operation. Intraoperative conditions included operation time, intraoperative blood loss, cases of intraoperative blood transfusion, remote cutting marginal distance of Dixon operation, number of assessable lymph glands, number of lymphoma transfer, and cases of terminal ileum fistulization of Dixon operation. Post-operative recovery included time of exhaustion, time of defecation, and time of feeding after operation and LOS. Complications observed were disruption of wound, infection of wound, bleeding of anastomotic stoma, anastomotic fistula, serious pulmonary infection, urinary tract infection, rectovaginal fistula, and uroschesis.

\section{Statistical analysis}

Relevant data were input into SPSS22.0. Relevant measurement data were expressed in $\bar{x} \pm s$ and examined by $t-$ test. Relevant enumeration data were expressed in $\%$ and examined by $\chi^{2}$-test. $\mathrm{P}<0.05$ indicated a statistically significant difference.

\section{Results}

\section{Operation mode}

No significant difference of operation mode (e.g., Dixon operation, Miles operation, and Hartmann operation) was observed between the treatment group and control group $(\mathrm{P}>0.05)$ (Table 1).

Table 1. Comparison of operation modes between two groups ( $n(\%))$.

\begin{tabular}{llll}
\hline Group & $\begin{array}{l}\text { Miles } \\
\text { operation }\end{array}$ & $\begin{array}{l}\text { Hartmann } \\
\text { operation }\end{array}$ & $\begin{array}{l}\text { Dixon } \\
\text { operation }\end{array}$ \\
\hline Control $(n=60)$ & $41(68.3)$ & $6(10.0)$ & $21(35.0)$ \\
\hline Treatment $(n=60)$ & $45(75.0)$ & $4(6.7)$ & $27(45.0)$ \\
\hline$X^{2}$ & 0.6566 & 0.4364 & 1.2500 \\
\hline$P$ & 0.4178 & 0.5089 & 0.2636 \\
\hline
\end{tabular}

\section{Basic intraoperative conditions}

The operation time of the control group was shorter than that of the treatment group, but the intraoperative blood loss of the treatment group was far higher $(\mathrm{P}<0.05)$ than that of the control group. No significant differences were found between the two groups in terms of the cases of intraoperative blood transfusion, remote cutting marginal distance of Dixon operation, number of assessable lymph glands, number of 
Comparison of short-term therapeutic effects between laparoscopic surgery and laparotomy combined with new adjuvant radiochemotherapy in progressive stage-rectal carcinoma

lymphoma transfer, and cases of terminal ileum fistulization of Dixon operation $(\mathrm{P}>0.05)$ (Table 2$)$.

Table 2. Comparison of basic intraoperative conditions between two groups.

\begin{tabular}{|c|c|c|c|c|}
\hline $\begin{array}{l}\text { Basic } \\
\text { intraoperative } \\
\text { condition }\end{array}$ & Control $(n=60)$ & Treatment $(n=60)$ & $t / x^{2}$ & $\mathbf{P}$ \\
\hline $\begin{array}{l}\text { Operation time } \\
(\mathrm{min})\end{array}$ & $132.6 \pm 38.4$ & $160.5 \pm 46.1$ & 3.7490 & 0.0003 \\
\hline $\begin{array}{l}\text { Intraoperative } \\
\text { blood loss (ml) }\end{array}$ & $232.5 \pm 116.3$ & $135.2 \pm 60.4$ & 5.9859 & 0.0000 \\
\hline $\begin{array}{l}\text { Cases of terminal } \\
\text { ileum fistulization of } \\
\text { Dixon operation } \\
\text { (cases) }\end{array}$ & $8(13.3)$ & $5(8.3)$ & 0.7764 & 0.3782 \\
\hline $\begin{array}{l}\text { Number } \\
\text { lymphoma } \\
\text { (pc) }\end{array}$ & $2.2 \pm 1.4$ & $1.9 \pm 1.5$ & 1.1787 & 0.2407 \\
\hline $\begin{array}{lr}\text { Number } & \text { of } \\
\text { assessable } & \text { lymph } \\
\text { glands }(p c) & \end{array}$ & $6.5 \pm 2.1$ & $6.3 \pm 1.7$ & 0.5967 & 0.5517 \\
\hline $\begin{array}{l}\text { Remoter cutting } \\
\text { marginal distance } \\
\text { of Dixon operation } \\
(\mathrm{cm})\end{array}$ & $4.2 \pm 1.7$ & $4.8 \pm 1.9$ & 1.8973 & 0.0600 \\
\hline $\begin{array}{l}\text { Cases of } \\
\text { intraoperative blood } \\
\text { transfusion (cases) }\end{array}$ & $12(20.0)$ & $8(13.3)$ & 0.9600 & 0.3272 \\
\hline
\end{tabular}

\section{Post-operative recovery}

Time of exhaustion, time of defecation and time of feeding after operation and LOS of the treatment group are shorter than those of the control group $(\mathrm{P}<0.05)$ (Table 3$)$.

Table 3. Comparison of post-operative recovery between two groups $(\bar{x} \pm s, d)$.

\begin{tabular}{|c|c|c|c|c|}
\hline Group & $\begin{array}{l}\text { Control group } \\
(n=60)\end{array}$ & $\begin{array}{l}\text { Treatment } \\
\text { group }(n=60)\end{array}$ & $t$ value & $P$ value \\
\hline $\begin{array}{l}\text { Time of } \\
\text { exhaustion }\end{array}$ & $3.9 \pm 0.9$ & $3.1 \pm 1.0$ & 4.7941 & 0.0000 \\
\hline $\begin{array}{l}\text { Time } \\
\text { defecation }\end{array}$ & $4.8 \pm 1.0$ & $4.1 \pm 0.7$ & 4.6234 & 0.0000 \\
\hline Time of feeding & $4.6 \pm 0.9$ & $3.7 \pm 0.8$ & 6.0258 & 0.0000 \\
\hline LOS & $14.9 \pm 4.1$ & $11.8 \pm 3.2$ & 4.8054 & 0.0000 \\
\hline
\end{tabular}

\section{Post-operative complications}

The control group and treatment group presented no statistically significant difference in the occurrence rate of post-operative complications $(\mathrm{P}<0.05)$ (Table 4).

Table 4. Comparison of post-operative complications between two groups $(n(\%))$.

Complication $\begin{aligned} & \text { Control group } \\ & (n=60)\end{aligned} \quad \begin{aligned} & \text { Treatment } \\ & \text { group }(n=60)\end{aligned} \quad X^{2}$ value $\quad P$ value

\begin{tabular}{|c|c|c|c|c|}
\hline Uroschesis & $5(8.3)$ & $3(5.0)$ & 0.5357 & 0.4642 \\
\hline $\begin{array}{l}\text { Serious } \\
\text { pulmonary } \\
\text { infection }\end{array}$ & $10(16.7)$ & $7(11.7)$ & 0.6168 & 0.4322 \\
\hline $\begin{array}{l}\text { Urinary tract } \\
\text { infection }\end{array}$ & $4(6.7)$ & $2(3.3)$ & 0.7018 & 0.40222 \\
\hline $\begin{array}{l}\text { Rectovaginal } \\
\text { fistula }\end{array}$ & $1(1.7)$ & $0(0.0)$ & 1.0084 & 0.3153 \\
\hline $\begin{array}{l}\text { Disruption of } \\
\text { wound }\end{array}$ & $2(3.3)$ & $0(0.0)$ & 2.0339 & 0.1538 \\
\hline $\begin{array}{l}\text { Infection } \\
\text { wound }\end{array}$ & $4(6.7)$ & $1(1.7)$ & 1.8783 & 0.1705 \\
\hline $\begin{array}{l}\text { Anastomotic } \\
\text { fistula }\end{array}$ & $3(5.0)$ & $1(1.7)$ & 1.0345 & 0.3091 \\
\hline $\begin{array}{l}\text { Bleeding of } \\
\text { anastomotic } \\
\text { stoma }\end{array}$ & $6(10.0)$ & $3(5.0)$ & 1.0811 & 0.2985 \\
\hline
\end{tabular}

\section{Discussion}

Rectal carcinoma in the progressive stage is a very common tumor type in clinics. Morbidity increases yearly due to the changes in the environment and lifestyle [5]. Rectal carcinoma has high fatality rate and threats the life of patients. Synchronous adjuvant radiochemotherapy before the operation reduces tumor volume mainly through local radiotherapy and general chemotherapy before the operation [6]. It can reduce local recurrence and clinical stages and increase excision effect. The application of radiochemotherapy of rectal carcinoma in the progressive stage has been extensively reported [7]. Although this therapy can cause a series of acute untoward effects (e.g., gastrointestinal tract infection and myelosuppression) in a short period, the total tolerance after a certain period is relatively ideal and operation is feasible [8].

Laparoscopic surgery can achieve long-term effect similar with that of laparotomy. It has advantages of minimally invasive, low occurrence rate of complications, quick recovery in a short period, and high clinical approval [9]. At present, few researches focus on the treatment of rectal carcinoma in the progressive stage by combining the new adjuvant radiochemotherapy as well as laparotomy and laparoscopic surgery. Although the treatment group took longer time to finish the operation than the control group in this study, intraoperative blood loss was fewer, which basically agrees with those of the conclusions of related literature. The new adjuvant radiochemotherapy can cause fibroplasias and tissue edema, which can prolong the overall operation time and increase operation difficulties and risks of short-term complications [10]. Sharp separation was performed with an ultrasound knife under a laparoscope, which can provide a clear operating field and reduce blood loss and inflammatory depth. Moreover, the new adjuvant radiochemotherapy not only guarantees general excision but also increases the rate of anal preservation compared with laparotomy. In this study, the two groups showed no significant differences in other indexes $(\mathrm{P}>0.05)$ and in the occurrence rate of post-operative complications $(\mathrm{P}>0.05)$. However, the treatment group 
underwent shorter time of exhaustion, time of defecation, and time of feeding after operation and LOS compared with the control group $(\mathrm{P}<0.05)$. This finding revealed the advantages of laparoscopic surgery. Early feeding after operation is good to facilitate gastrointestinal function recovery and nutritional supplement while reducing the risks of complications.

\section{Conclusion}

Laparoscopic surgery combined with new adjuvant radiochemotherapy has outstanding therapeutic effect on rectal carcinoma in the progressive stage and exhibits high safety. Therefore, this can be promoted as the first clinical therapy for patients with rectal carcinoma in the progressive stage.

\section{References}

1. Iott M, Neben-Wittich M, Quevedo JF, Miller RC. Adjuvant chemoradiotherapy for resected pancreas cancer. World J Gastrointest Surg 2010; 2: 373-380.

2. Ruan FC, Dai J, Yan QH, Lu Y. Altered metabolic behavior of derivatives of herbal compounds used for treatment of carcinoma of mouth. Lat Am J Pharm 2017; 36: 1730-1735.

3. Peng J, Wei Y, Zhou F, Dai J, Zhong Y, Xie C, Qin Y, Gong J, Xiong B, Zhou Y. D2-resected stage IIIc gastric cancer patients benefit from adjuvant chemoradiotherapy. Cancer Med 2016; 5: 2773-2780.

4. Dai Y, Dong J, Qin W. Pyloric obstruction due to gastric bezoar: 3D laparoscopic-assisted removal of bezoar. Biomed Res India 2017; 28: 4367-4368

5. Wang SJ, Lemieux A, Kalpathy-Cramer J, Ord CB, Walker GV, Fuller CD, Kim JS, Thomas CR. Nomogram for predicting the benefit of adjuvant chemoradiotherapy for resected gallbladder cancer. J Clin Oncol 2011; 29: 4627-4632.

6. Zhang XF, Chen Y, Wang JJ. Renal cell carcinoma treatment drug everolimus inhibited udpglucuronosyltransferase (UGT) 1A6. Lat Am J Pharm 2017; 36: 1284-1288.

7. Pascual M, Salvans S, Pera M. Laparoscopic colorectal surgery: Current status and implementation of the latest technological innovations. World J Gastroenterol 2016; 22: 704-717.

8. Liu S, Tian M. Minimum effective concentration for the inhibitory effect of remifentanil on circulatory response due to pneumoperitoneum during laparoscopic surgery in elderly patients. Biomed Res India 2017; 28: 4380-4385.

9. Gupta A, Habib K, Harikrishnan A, Khetan N. Laparoscopic surgery in luminal gastrointestinal emergencies-a review of current status. Indian J Surg 2014; 76: 436-443.

10. Buia A, Stockhausen F, Hanisch E. Laparoscopic surgery: a qualified systematic review. World J Methodol 2015; 5: 238-254.

\section{*Correspondence to}

Jianhua Meng

Department of Oncology

The Second Hospital of Wuhan Iron And Steet (Group) CORP

PR China 